\title{
ANALISIS PENGGUNAAN GULA PASIR SEBAGAI RETARDER PADA BETON
}

\author{
Adzuha Desmi \\ Jurusan Teknik Sipil, Fakultas Teknik, Universitas Malikussaleh \\ Email :adz.5esmi@gmail.com
}

\begin{abstract}
Abstrak
Retarder merupakan bahan kimia pembantu untuk memperlambat waktu pengikatan (setting time) sehingga campuran akan tetap mudah dikerjakan (workable) untuk waktu yang lebih lama. Penggunaan untuk menunda waktu pengikatan beton (setting time) misalnya dengan kondisi cuaca yang panas, atau memperpanjang waktu pemadatan untuk menghindari cold joint dan menghindari dampak penurunan saat beton segar pada saat pengecoran dilaksanakan. Penelitian ini bertujuan untuk mengetahui perubahan perilaku beton terhadap penambahan kadar gula pasir sebagai retarder, dan untuk mengetahui perbandingan sifat-sifat beton yang menggunakan gula pasir dan tanpa menggunakan gula pasir. Persentase penambahan kadar gula pasir $0,15 \%$, $0,30 \%$ dan $0,45 \%$ dari berat semen. Setiap variasi dan persentase kadar gula pasir di buat benda uji sebanyak 3 benda uji untuk pengujian tes Vicat, yaitu semen bila dicampur dengan air akan menghasilkan pasta yang plastis dan lecak. Namun setelah selang beberapa waktu, pasta akan mulai menjadi kaku dan sukar dikerjakan, inilah yang disebut pengikatan awal (initial set). Selanjutnya pasta akan meningkat kekuatannya sehingga didapatkan padatan yang utuh, ini disebut pengikatan akhir (final set). Proses berlanjut hingga pasta mempunyai kekuatan, disebut pengerasan (hardening). Hasil uji Vicat menunjukkan perlambatan pengerasan penundaan yang maksimum terjadi pada kadar gula pasir $0,45 \%$, sedangkan pada kadar gula pasir $0,00 \%$ terjadi penundaan pengerasan secara normal. Jadi penambahan kadar gula pasir $0,15 \%$ sampai $0,45 \%$ dapat dianggap sebagai Retarder.
\end{abstract}

Kata Kunci : retarder, gula pasir, tes vicat, initial set, final set.

\section{Pendahuluan}

Retarder adalah bahan kimia pembantu untuk memperlambat waktu pengikatan (setting time) sehingga campuran akan tetap mudah dikerjakan (workable) untuk waktu yang lebih lama. Temperatur setinggi $30-32{ }^{\circ} \mathrm{C}$ atau lebih sering menyebabkan makin cepatnya hardening, yang menyebabkan sukarnya penuangan dan penyelesain. Retarder pada umumnya bahan dasar yang mengandung gula (sugar-based). Mekanisme cara kerja retarder yaitu membungkus butir semen dengan $\mathrm{OH}^{-}$sehingga memperlambat reaksi awal dari hidrasinya. Terbentuknya garam Ca dalam air mengurangi konsentrasi ion $\mathrm{Ca}$ dan memperlambat kristalisasi selama fase hidrasi.

Pemakaian yang berlebihan akan menyebabkan perlambatan yang berlebihan, tetapi kekuatan akan meningkat dengan normal setelah periode perlambatan selesai, asalkan curing tetap dilakukan dan bekisting tidak di ubah. Kegunaan retarder yaitu memperlambat waktu pengikatan (set) dan pengerasan (hardening). Akibat sampingannya adalah menaikkan kekuatan akhir beton karena ; (1). Mengurangi kecepatan evolusi panas (untuk pengecoran yang luas 
dalam cuaca panas), (2). Menghindari terjadinya sambungan dingin (cold joint), yaitu pada pengecoran beton masif di mana pengecoran lapisan demi lapisan memakan waktu yang cukup lama atau pengecoran yang terganggu, (3). Untuk pengangkutan yang lama, misalnya pada pembuatan beton jadi (ready mix), menunda waktu pengikatan awal (initial set) dengan tetap menjaga workabilitasnya, (4). Untuk kondisi penuangan yang sulit dan tidak umum, seperti pada pier dan fondasi besar, menyemen sumur minyak atau memompa grout atau beton untuk jarak yang panjang.

Kelemahan retarder yaitu; (1). Ada resiko pemisahan (Segregasi), (2). Dapat memperbesar susut plastis, (3). Ada tendensi pengurangan kekuatan pada umur dini (1 sampai 3 hari) (Paul Nugraha Antoni, 2007).

Retarder Admixture adalah bahan tambah yang berfungsi untuk menghambat waktu pengikatan beton. Penggunaan untuk menunda waktu pengikatan beton (setting time) misalnya dengan kondisi cuaca yang panas, atau memperpanjang waktu pemadatan untuk menghindari cold joint dan menghindari dampak penurunan saat beton segar pada saat pengecoran dilaksanakan (Mulyono, 2003). Zat kimia untuk memperlambat proses ikatan campuran beton (Retarder). Zat tambahan diantaranya berupa gula, sucrose, sodium gluconate, glucose, citric acid dan tartaric acid, (Ahmad Basuki, 2012). Bahan tambah (admixture) adalah bahan-bahan yang ditambahkan ke dalam campuran beton pada saat atau selama pencampuran berlangsung. Fungsi dari bahan ini adalah untuk mengubah sifatsifat dari beton agar menjadi lebih cocok untuk pekerjaan tertentu, atau untuk menghemat biaya.

Penambahan bahan tambah dalam sebuah campuran beton atau mortal tidak mengubah komposisi yang besar dari bahan yang lainnya, karena penggunaan bahan tambah ini cenderung merupakan pengganti atau substitusi dari dalam campuran beton itu sendiri. Karena tujuannya memperbaiki atau mengubah sifat dan karakteristik tertentu dari beton atau mortal yang akan dihasilkan, maka kecenderungan perubahan komposisi dalam berat volume tidak terasa langsung dibandingkan dengan komposisi awal beton tanpa bahan tambah.

Pokok permasalahan yang akan dibahas dalam tulisan ini adalah ; (1). Untuk mengetahui bagaimana pengaruh penambahan kadar gula pasir terhadap retarder dengan persentase kadar gula pasir $0.15 \%, 0,30 \%$ dan $0,45 \%$, (2). Untuk mengetahui perubahan perilaku beton terhadap penambahan kadar gula pasir sebagai retarder, (3). Untuk mengetahui perbandingan sifat-sifat beton yang menggunakan gula pasir dan tanpa menggunakan gula pasir.

\section{Tinjauan Kepustakaan}

Beton merupakan komponen utama suatu struktur bangunan yang berfungsi sebagai penyokong beban sehingga perencanaan dalam mendesain suatu struktur bangunan harus menentukan mutu dari beton yang akan digunakan. Perhitungan yang akurat mengenai mutu beton disesuaikan dengan mutu beton rencana, karena merupakan suatu keharusan yang memberikan kunci dari keamanan dan kelayakan struktur bangunan. Terutama sekali bangunan yang penggunaannya 
untuk umum. Menurut Mulyono (2003), Dalam keadaan yang mengeras, beton bagaikan batu karang dengan kekuatan tinggi. Dalam keadaan segar, beton dapat diberi berbagai macam bentuk, sehingga dapat digunakan untuk membentuk seni arsitektur atau semata - mata untuk tujuan dekoratif. Selain tahan terhadap serangan api, beton juga tahan terhadap serangan korosi. Sebagian besar bahan pembuat beton adalah bahan lokal (kecuali semen Portland atau bahan tambah kimia) sehingga sangat menguntungkan secara ekonomi. Namun, pembuatan beton akan menjadi mahal jika perencana tidak memahami karakteristik bahanbahan penyusun beton yang harus disesuaikan dengan struktur yang akan dibuat.

\subsection{Gula}

Gula adalah salah satu karbohidrat terpenting yang digunakan sebagai sumber tenaga. Gula merupakan salah satu hasil fotosintesis dan awal bagi respirasi. Bentuk alami (D-glukosa) disebut juga dekstrsa. Menurut Paul Nugraha Antoni (2007), sejumlah kecil gula, 0,03 sampai $0,15 \%$ berat semen, umumnya memperlambat pengikatan semen. Batas atas bervariasi dengan jenis semen. Kekuatan 7 hari dapat dikurangi sementara kekuatan 28 hari dapat dinaikkan. Ketika jumlah gula bertambah sampai $0,20 \%$ berat semen, pengikatan umumnya bertambah cepat. Gula dalam kadar $0,25 \%$ atau lebih berat dapat menyebabkan pengikatan yang cepat dan pengurangan kekuatan 28 hari.

\subsection{Air}

Menurut Paul Nugraha Antoni (2007), air adalah alat untuk mendapatkan kelecakan yang perlu untuk penuangan beton. Jumlah air yang diperlukan untuk kelecakan tertentu tergantung pada sifat material yang digunakan . Hukum kadar air konstan mengatakan. Kadar air yang diperlukan untuk kelecakan tertentu hampir konstan tanpa tergantung pada jumlah semen, untuk kombinasi agregat halus dan kasar tertentu. Menurut Mulyono (2003), air sangat diperlukan pada pembuatan beton untuk memicu proses kimiawi semen, membasahi agregat dan memberikan kemudahan dalam pekerjaan beton. Air yang dapat diminum umumnya dapat digunakan sebagai campuran beton. Air yang mengandung senyawa-senyawa yang berbahaya, yang tercemar garam, minyak, gula, atau bahan kimia lainnya, bila dipakai dalam campuran beton akan menurunkan kualitas beton, bahkan dapat mengubah sifat-sifat beton yang dihasilkan.

\subsection{Pengujian Sifat - Sifat Fisis Material}

Menurut Hanafiah (1994), kandungan air agregat adalah banyaknya air yang terdapat dalam agregat tersebut dalam satuan berat dibandingkan dengan berat keseluruhan dari agregat. Pemeriksaan ini bertujuan untuk mengetahui banyaknya air yang terkandung dalam pasir saat akan di aduk menjadi campuran beton. Dengan diketahui kandungan air, air campuran beton dapat disesuiakan agar factor air semen (water cement ratio) yang diambil konstan.

\subsection{Pemeriksaan berat volume (bulk density)}

Berat volume agregat adalah perbandingan antara berat agregat kering dengan volume yang ditempatinya. Hal ini dapat digunakan untuk mempermudah perhitungan campuran beton bila dilakukan penimbangan agregat dengan ukuran volume. 
Menurut Orchard (1979), berat volume digunakan sebagai konversi, dari volume menjadi berat agregat atau sebaliknya dalam perhitungan rancangan campuran beton. Berat volume agregat yang baik untuk material beton mempunyai nilai lebih besar dari $1,445 \mathrm{~kg} / \mathrm{l}$. Berat volume agregat adalah perbandingan antara berat agregat dengan volume agregat. Semakin besar nilai berat volume agregat menandakan semakin padat dan semakin keras agregat tersebut dan kekuatan hancurnya juga semakin besar, sehingga beton yang menggunakan agregat tersebut akan mempunyai nilai kepadatan dan kuat tekan yang semakin besar juga. Berat volume dapat dihitung dengan menggunakan persamaan sebagai berikut:

$$
\text { Berat volume agregat }=\frac{W_{S}}{V}\left(\mathrm{~kg} / \mathrm{m}^{3}\right)
$$

di mana; Ws = Berat benda uji $(\mathrm{kg}) ; \mathrm{V}=$ Volume wadah $/$ Container $\left(\mathrm{M}^{3}\right)$.

\subsection{Analisa saringan (sieve analysis)}

Analisa saringan adalah suatu kegiatan analisis untuk mengetahui distribusi ukuran agregat baik kasar maupun halus dengan menggunakan ukuran-ukuran saringan standar tertentu yang ditunjukkan dengan lubang saringan (mm). Pemeriksaan terhadap susunan butir agregat (gradasi) bertujuan untuk menilai agregat halus dan kasar yang digunakan pada campuran beton. Susunan butir agregat diperoleh dari hasil penyaringan agregat dengan menggunakan beberapa fraksi saringan. Batas maksimum butiran 31,5 mm dan batas minimum 0,075 mm. Campuran beton yang direncanakan (mix design) harus memakai agregat dengan gradasi yang baik, untuk itu dilakukan analisis saringan terhadap agregat yang digunakan. Derajat kehalusan (Fineness modulus) agregat dihitung berdasarkan persentase berat agregat yang tinggal diatas tiap saringan. Nilai derajat kehalusan (Fineness modulus) untuk tiap jenis agregat dapat dihitung dari kumulatif persentase berat agregat yang tertahan diatas saringan. Nilai modulus kehalusan kerikil adalah $(5,5-8,0)$, untuk pasir kasar adalah $(2,9-3,2)$, Untuk pasir halus adalah $(2,2-2,6)$, dan untuk agregat campuran adalah $(4,0-7,0)$. Untuk mencari modulus kehalusan (FM) dapat harus ditentukan :

$$
\text { Persentase tertahan }=\frac{\text { Berat Tertahan } \mathrm{x} 100}{\text { Berat Benda Uji }}
$$

$\%$ lolos kumulatif $=\%$ lolos kumulatif baris pertama $-\%$ tertahan baris kedua

$$
\begin{aligned}
& \% \text { tertahan kumulatif }=100-\% \text { lolos kumulatif ............................... }
\end{aligned}
$$

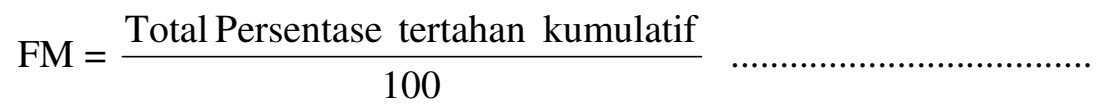

\subsection{Pengujian kandungan air (moisture content)}

Menurut Hanafiah (1994), kandungan air agregat adalah banyaknya air yang terdapat dalam agregat tersebut dalam satuan berat dibandingkan dengan berat keseluruhan dari agregat. Pemeriksaan ini bertujuan untuk mengetahui banyaknya air yang terkandung dalam pasir saat akan di aduk menjadi campuran beton. 
Dengan diketahui kandungan air, air campuran beton dapat disesuiakan agar factor air semen (water cement ratio) yang diambil konstan. Banyaknya air yang terkandung dalam agregat kering permukaan dapat dihitung dengan menggunakan persamaan :

$$
\mathrm{P}=\frac{W v-W v^{\prime}}{W s-W v^{\prime}} x 100 \%
$$

Di mana ; $\mathrm{W}_{\mathrm{S}}=$ Berat benda uji (gram); $\mathrm{W}_{\mathrm{V}}=$ Berat agregat natural (gram); $\mathrm{W}_{\mathrm{V}}$, $=$ Berat agregat dalam keadaan kering permukaan (gram).

Kandungan air dalam keadaan kering oven dapat dihitung dengan menggunakan persamaan:

$$
\mathrm{P}^{\prime}=\frac{W v-W v^{\prime}}{W s-W v^{\prime}} \times 100 \%
$$

Di mana: $\mathrm{W}_{\mathrm{S}}=$ Berat benda uji (gram); $\mathrm{W}_{\mathrm{V}}=$ Berat agregat natural (gram); $\mathrm{W}_{\mathrm{V}^{\prime}}=$ Berat agregat dalam keadaan kering oven (gram).

Pemeriksaan ini berlaku untuk pasir kasar dan pasir halus terhadap pemeriksaan dalam keadaan kering permukaan dan keadaan kering oven.

\subsection{Pengujian berat jenis semen}

Pemeriksaan terhadap semen dilakukan dengan cara visual yaitu semen dalam keadaan tertutup rapat dan setelah dibuka tidak ada gumpalan serta butirannya halus. Semen yang digunakan dalam penelitian ini adalah semen Andalas kemasan $40 \mathrm{~kg}$.

\subsection{Pengujian Konsistensi Normal (ASTM C. 187 - 79)}

Konsistensi normal adalah banyaknya air campuran dalam pasta semen untuk menentukan waktu pengikatan semen standar.

$$
\text { Konsistensi }=\frac{\text { BeratAir }}{\text { BeratSemen }} x 100 \%
$$

\subsection{Pengujian Vicat (pengikatan awal dan akhir)}

Pengikatan awal semen adalah jangka waktu mulainya pengukuran pasta semen pada konsistensi normal semen hingga pasta semen kehilangan sebagian sifat plastis, (ASTM C.191-77). Tujuan Pengikatan awal semen untuk mendapatkan waktu pengikatan awal semen dalam keadaan konsistensi normal dengan alat vicat, dengan menggunakan rumus di bawah ini :

$\mathrm{T}$ awal $=$ to $+30+\mathrm{t}$ grafik

$$
\mathrm{T} \text { akhir }=\text { to }+30+\mathrm{t} \text { akhir }
$$

Semen bila dicampur dengan air akan menghasilkan pasta yang plastis dan lecak (workable). Namun setelah selang beberapa waktu, pasta akan mulai menjadi kaku dan sukar dikerjakan. Inilah yang disebut pengikatan awal (initial set). Selanjutnya pasta akan meningkat kekuatannya sehingga didapatkan 
padatan yang utuh. Ini disebut pengikatan akhir (final set). Proses berlanjut hingga pasta mempunyai kekuatan, disebut pengerasan (hardening).

\section{Metode Penelitian}

Penelitian ini dibagi atas beberapa tahap pengujian yaitu tahap penelitian material, tahap rendaman dan kuat tekan beton. Pelaksanaan metode penelitian yang dilakukan meliputi hal-hal Persiapan bahan, Alat-alat yang digunakan, Pelaksaan penelitian, Pembuatan benda uji, Pengujian konsistensi normal, Pengujian pengikatan awal dan pengikatan akhir. Penelitian ini dilanjutkan dengan persiapan data dan material yaitu: agregat, semen, gula pasir dan air. Pemeriksaan sifat-sifat fisik dan kandungan bahan organik agregat dilakukan sebelum perencanaan campuran beton, ini bertujuan untuk mengetahui apakah material yang digunakan memenuhi syarat sebagai bahan material pembentuk beton yang baik. Selanjutnya dilakukan Pengujian Konsistensi Normal (ASTM C. 187 - 79), Alat-alat yang digunakan dalam pengujian ini adalah Mesin pengaduk (mixer mortar) dengan daun pengaduk dari logam tahan karat, Alat Vicat, Timbangan dengan ketelitian 0,1 gram, Sendok perata (Spatula), Gelas/tabung ukur bervolume $100 \mathrm{cc},(6)$. Plat kaca, Sarung tangan karet, Stop watch, Cincin konik. Bahan-bahan yang digunakan dalam pengujian ini adalah Semen andalas PPC strip biru, Air suling (air bersih).

\section{Hasil dan Pembahasan}

\subsection{Hasil Pengujian Sifat Fisis Agregat}

Pengujian sifat fisis agregat ini meliputi pengujian berat jenis, berat volume, analisa saringan dan kadar air, akan dijelaskan hasil dari pengujian-pengujian agregat seperti tersebut diatas.

\subsubsection{Berat jenis dan absorbsi agregat}

Dari hasil pengujian berat jenis serta absorbsi agregat diperlihatkan pada Tabel 1 di bawah ini :

Tabel 1 Hasil Pengujian Berat Jenis dan Absorbsi Agregat

\begin{tabular}{|l|l|c|c|c|}
\hline No. & Jenis Agregat & $\mathrm{Sg}(\mathrm{ssd})\left(\mathrm{gr} / \mathrm{cm}^{3}\right)$ & $\mathrm{Sg}(\mathrm{od})\left(\mathrm{gr} / \mathrm{cm}^{3}\right)$ & Absorbsi (\%) \\
\hline & Pasir Halus & 2,66 & 2,62 & 1,68 \\
& Pasir Kasar & 2,69 & 2,59 & 4,10 \\
\hline
\end{tabular}

\subsubsection{Berat volume (bulk density)}

Dari hasil pengujian berat volume agregat memperlihatkan, nilai rata-rata berat volume agregat halus dan agregat kasar disajikan pada Table 2 dan 3 di bawah ini :

Tabel 2 Hasil Pengujian Berat Volume Agregat Gembur

\begin{tabular}{|c|c|c|}
\hline No & Jenis Agregat & Berat Volume (kg/ltr) \\
\hline 1. & Berat volume agregat halus & 1,448 \\
2. & Berat volume agregat kasar & 1,387 \\
\hline
\end{tabular}


Tabel 4.3 Hasil Pengujian Berat Volume Agregat Padat

\begin{tabular}{|c|c|c|}
\hline No & Jenis Agregat & Berat Volume (kg/ltr) \\
\hline 1. & Berat volume agregat halus & 1,564 \\
2. & Berat volume agregat kasar & 1,480 \\
\hline
\end{tabular}

\subsubsection{Analisa saringan (sieve analysis)}

Susunan butiran agregat halus ditampilkan dalam bentuk grafik seperti pada Gambar 1.

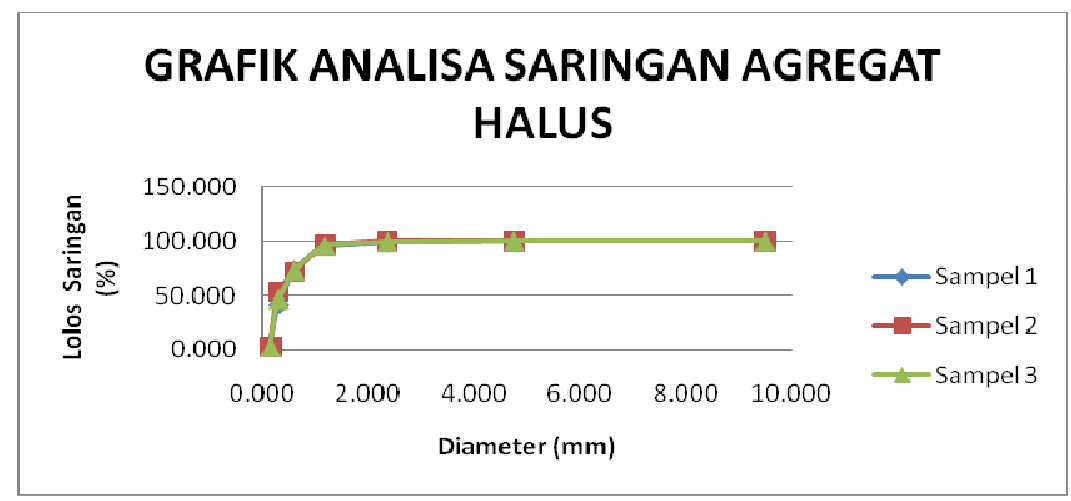

Gambar 1 Grafik Gradasi Agregat Halus Krueng Mane

Susunan butiran agregat kasar ditampilkan dalam bentuk grafik seperti pada Gambar 2.

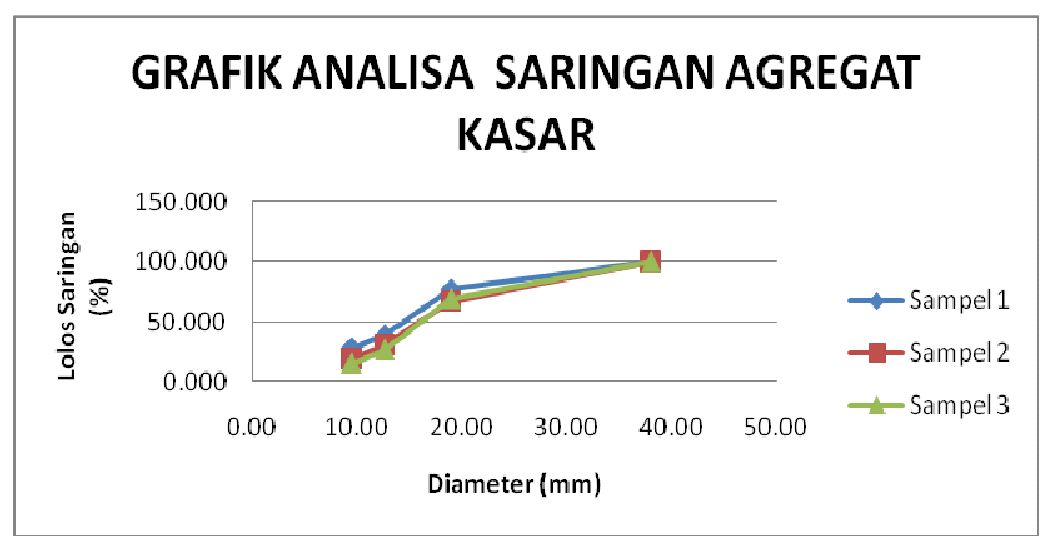

Gambar 2 Grafik Gradasi Agregat Kasar Krueng Mane.

Menurut grafik diatas dapat kita simpulkan bahwa agregat halus dan agregat kasar Krueng Mane dapat digunakan, karena tidak mengandung bagian yang lolos pada satu set ayakan lebih besar dari $45 \%$ dan tertahan pada ayakan berikutnya.

\subsubsection{Pengujian Kadar air (moisture content)}

Dari hasil pengujian diperoleh kadar air agregat halus sebesar 1,49\% dan kadar air agregat kasar sebesar 1,09\%. 


\subsubsection{Pengujian Vicat Test (Pengikatan Awal dan Akhir)}

Hasil Pengujian Vicat atau pengikatan awal dan pengikatan akhir seperti diperlihatkan pada Tabel 4

Tabel 4 Hasil Pengujian Pengikatan Awal dan Akhir

\begin{tabular}{|c|c|c|c|}
\hline No. & $\begin{array}{c}\text { Kadar gula pasir } \\
(\%)\end{array}$ & $\begin{array}{c}\text { Waktu pengikatan } \\
\text { awal (menit) }\end{array}$ & $\begin{array}{c}\text { Waktu pengikatan } \\
\text { akhir (menit) }\end{array}$ \\
\hline 1. & 0,00 & 105,88 & 129,21 \\
2. & 0.15 & 254,41 & 394,41 \\
3. & 0,30 & 321,08 & 514,41 \\
4. & 0,45 & 387,74 & 604,41 \\
\hline
\end{tabular}

\subsection{Pembahasan}

\subsubsection{Berat jenis dan absorbsi agregat}

Berdasarkan hasil perhitungan diperoleh nilai berat jenis agregat halus (SSD) yaitu sebesar 2,66 dan nilai (OD) sebesar 2,62 dan nilai berat jenis agregat kasar (SSD) yaitu sebesar 2,69 dan nilai (OD) sebesar 2,59, ini sesuai dengan yang disebutkan oleh Tri Mulyono tentang hubungan antara berat jenis dengan daya serap air. Jika semakin tinggi nilai berat jenis agregat maka semakin kecil daya serap air agregat tersebut.

\subsubsection{Berat volume (bulk density)}

Menurut Orchard (1979), bahwa berat volume agregat yang baik harus lebih besar dari pada 1,445 kg/ltr. Berat volume gembur sebesar $1,448 \mathrm{~kg} / \mathrm{ltr}$ dan berat volume padat sebesar $1,564 \mathrm{~kg} / \mathrm{ltr}$.

\subsubsection{Analisa saringan (sieve analysis)}

Berdasarkan hasil perhitungan diperoleh nilai fineness modulus agregat halus yaitu sebesar 2,818 dan nilai fineness modulus pasir kasar yaitu sebesar 3,754 .

\subsubsection{Pengujian Kadar air}

Berdasarkan hasil pemeriksaan kadar air agregat yang diperoleh kadar air agregat halus rata-rata sebesar $1,49 \%$ dan kadar air agregat kasar rata-rata sebesar $1,04 \%$

\subsubsection{Pengujian Kosistensi Normal}

Berdasarkan hasil uji konsistensi normal yang telah dilakukan dalam penelitian ini, Pada penurunan jarum vicat $1 \mathrm{~cm}$ diperoleh kadar air sebesar 79.5 gram.

\subsubsection{Pengujian Vicat Test (Pengikatan Awal dan Akhir)}

Berdasarkan hasil uji Vicat ditampilkan dalam bentuk grafik seperti pada Gambar 3 di bawah ini. 


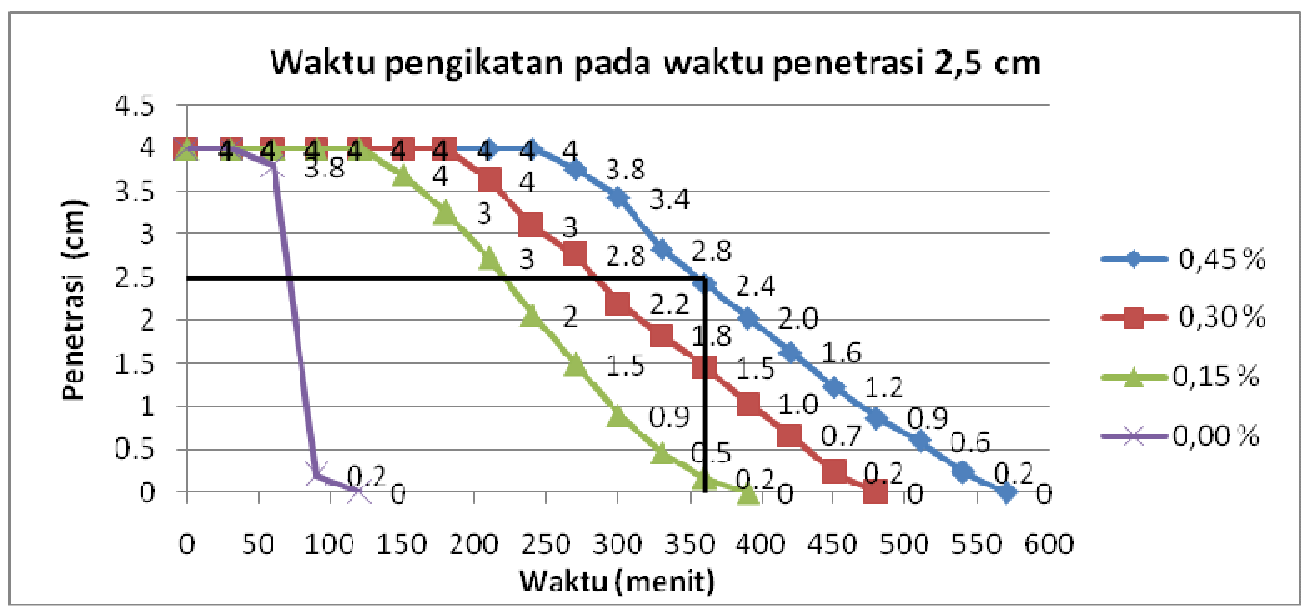

Gambar 3 grafik uji vicat penambahan kadar gula pasir dan tanpa penambahan gula pasir

Dari hasil penelitian memperlihatkan bahwa berdasarkan grafik diatas, penambahan kadar gula pasir berpengaruh terhadap perlambatan pengerasan (Retarder). Pada kadar gula pasir $0,00 \%$ pengikatan awal 105,88 menit dan pengikatan akhir 129,21 menit. Terjadi peningkatan pada kadar gula pasir $0,15 \%$ pengikatan awal 254,41 menit dan pengikatan akhir 394,41 menit, kadar gula pasir $0,30 \%$ pengikatan awal 321,08 menit dan pengikatan akhir 514,41 menit, kadar gula pasir $0,45 \%$ pengikatan awal 387,74 menit dan pengikatan akhir 604,41 menit, terjadi peningkatan maksimum pada kadar gula pasir 0,45\%, pengikatan awal 6,5 jam dan pengikatan akhir 10 jam.

\section{Kesimpulan dan Saran}

\subsection{Kesimpulan}

Dari hasil penelitian perilaku penambahan kadar gula pasir sebagai Retarder bahan tambah sebagian dari berat semen, dapat di ambil kesimpulan sebagai berikut:

1. Hasil penelitian menghasilkan perpanjangan waktu pengikatan awal optimum, variasi waktu penundaan pemadatan menunjukkan pada jumlah kadar gula pasir $0.15 \%$ adalah 6,5 jam, pada jumlah kadar gula pasir $0.30 \%$ adalah 8 jam, dan pada jumlah kadar gula pasir $0.45 \%$ adalah 9,5 jam.

2. Hasil uji Vicat menunjukkan perlambatan pengerasan yang maksimum terjadi pada kadar gula pasir $0.45 \%$, sedangkan pada kadar gula pasir $0.00 \%$ terjadi penundaan pengerasan secara normal. Jadi penambahan kadar gula pasir $0.15 \%$ sampai $0,45 \%$ dapat dianggap sebagai Retarder

3. Pengujian mortar dengan perbandingan $1: 3: 5$ beton $\mathrm{K}: 100$ dengan mutu 7,5 Mpa, tidak mempengaruhi nilai kuat tekan atau tidak berpengaruh terhadap penurunan nilai kuat tekan selama proses Retarder.

\subsection{Saran}

Dari hasil yang diperoleh dalam pengkajian laboratorium, ada beberapa saran yang akan dipaparkan, sehingga dapat berguna pada masa mendatang, antara lain : 
1. Diharapkan adanya penelitian lanjutan dengan menggunakan kadar gula pasir $0.45 \%$ sampai $1 \%$.

2. Diharapkan ada pengembangan untuk penelitian selanjutnya tidak hanya mengunakan gula pasir sebagai bahan tambah, tetapi juga bisa menggunakan bahan-bahan lain yang seperti sucrose, sodium gluconate, glucose, citric acid dan tartaric acid.

\section{Daftar Kepustakaan}

ASTM. C.494 1995, Jenis Bahan Tambah Kimia.

Mulyono. T, 2003, Teknologi Beton, Andi, Yogyakarta.

Murdock, L.J, dan Brook, K.M, 1999, Bahan dan Praktek Beton, Hendarto, S, Erlangga Jakarta.

Paul Nugraha Antoni, 2007, Teknologi Beton, Andi, Yogyakarta.

Robert Indarko Ganis, Hartaman Aris Nugraha, 2008, Pengaruh larutan tebu 0,03 $\%$ sebagai retarder alami terhadap kuat tekan beton

http://eprints.unika.ac.id/1453/1/04.12.0005_Robert_Indarko_Ganis_\%2B_04.12. 0039_Hartaman_Aris_Nugraha.pdf. 